\title{
DETERMINAN MINAT INDIVIDU MENGGUNAKAN LAYANAN FINANCIAL TECHNOLOGY DENGAN KERANGKA INNOVATION DIFFUSION THEORY
}

\author{
Rada Nur Indriyati \\ Prodi Akuntansi Universitas Negeri Yogyakarta \\ radanurindr@gmail.com \\ Mimin Nur Aisyah \\ Staf Pengajar Jurusan Pendidikan Akuntansi Universitas Negeri Yogyakarta \\ mimin_nuraisyah@uny.ac.id
}

\begin{abstract}
Abstrak: Determinan Minat Individu Menggunakan Layanan Financial Technology dengan Kerangka Innovation Diffusion Theory. Penelitian ini bertujuan untuk mengetahui faktor-faktor yang mempengaruhi minat individu menggunakan layanan fintech dengan kerangka Innovation Diffusion Theory (IDT). Penelitian ini merupakan explanatory research. Sampel penelitian adalah 100 pengguna layanan fintech di Kota Yogyakarta yang diperoleh dengan teknik convenience sampling. Metode analisis yang digunakan yaitu Structural Equation Modeling (SEM) dengan menggunakan Partial Least Square (PLS). Hasil penelitian ini menunjukkan bahwa relative advantage, compatibility, trialability, dan observability berpengaruh positif terhadap minat individu menggunakan layanan financial technology di Kota Yogyakarta, sedangkan complexity berpengaruh negatif terhadap minat individu menggunakan layanan financial technology di Kota Yogyakarta.
\end{abstract}

Kata kunci: Innovation Diffusion Theory (IDT), Layanan Financial Technology, Karakteristik inovasi.

Abstract: Determinant of Individual Interest in Using Financial Technology Services with Innovation Diffusion Theory Framework. This research aims at determining the factors influencing individual interest in using financial technology services by Innovation Diffusion Theory (IDT) framework. It is an explanatory research involving data collected from a hundred users of financial technology in Yogyakarta through convenience sampling method. The data was analyzed by using Structural Equation Model (SEM) with Partial Least Square (PLS) analysis. The result of this research shows that relative advantage, compatibility, trialability, and observability positively affect individual interest in using financial technology services in Yogyakarta district meanwhile, complexity negatively affects individual interest in using financial technology services.

Keywords: Innovation Diffusion Theory (IDT), Financial Technology Services, Innovative Characteristics

\section{PENDAHULUAN}

Seiring dengan berkembangnya zaman, hadirnya globalisasi di era millenial ini telah membawa dampak yang besar di seluruh sektor kehidupan manusia termasuk salah satunya adalah teknologi. Teknologi informasi telah menjadi bagian yang tidak bisa dipisahkan dalam kehidupan seharihari manusia. Teknologi memegang peranan penting dalam menunjang kenyamanan dan kemudahan manusia dalam melakukan berbagai aktivitas seharihari, seiring dengan meningkatnya aktivitas manusia. 


\section{JURNAL NOMINAL / VOLUME VIII NOMOR 2 / TAHUN 2019}

Pada saat ini keuangan merupakan salah satu sektor yang mendukung kekuatan perekonomian negara dan memegang peranan yang sangat signifikan dalam memicu pertumbuhan perekonomian negara. Hal tersebut terbukti dengan hadirnya inovasi terbaru dalam bidang keuangan, yaitu financial technology atau sering disebut dengan fintech.

Fintech telah memberikan warna baru dalam dunia finansial. Financial technology merupakan salah satu pertanda berkembangnya teknologi pada masa kini, yang dimanfaatkan untuk meningkatkan layanan jasa keuangan karena teknologi finansial dirasa mampu memberikan solusi bagi bagi pertumbuhan industri berbasis elektronik.

Menurut studi berjudul Fintech and the Evolving Landscape, investasi perusahaan fintech di Asia-Pasifik meningkat selama kuartal pertama 2016 yang mencapai AS\$ 2,7 miliar, mewakili 50\% dari AS\$ 5,3 miliar yang diinvestasikan ke perusahaan fintech global (Accenture, 2016).

Di Indonesia, Financial Technology diatur oleh Bank Indonesia dalam Peraturan Bank Indonesia (PBI) No. 18/40/PBI/2016 tentang Penyelenggaraan Pemrosesan Transaksi Pembayaran dan Peraturan Bank Indonesia (PBI) No. 19/12/PBI/2017 tentang Penyelenggaraan Teknologi Finansial, Bab I Pasal 1, point 1 yang menyatakan bahwa teknologi finansial adalah penggunaan teknologi dalam sistem keuangan yang menghasilkan produk, layanan, teknologi, dan/atau model bisnis baru serta dapat berdampak pada stabilitas moneter, stabilitas sistem keuangan, dan/atau efisiensi, kelancaran, keamanan, dan keandalan sistem pembayaran.

Transaksi pembayaran dengan menggunakan uang tunai sudah mulai tergantikan dengan sistem pembayaran non-tunai karena perubahan sistem pembayaran menggunakan Less Cash Society adalah hal yang tidak dapat dihindari. Less Cash Society merupakan tren yang berkembang di masyarakat dalam melakukan transaksi pembayaran melalui media pembayaran non-tunai.

Berdasarkan riset Google dan Temasek, adopsi layanan pembayaran digital di Indonesia sudah mencapai angka $46 \%$ yang artinya 1 dari 2 pengguna internet telah bertransaksi secara digital (E-conomy SEA, 2018). Hasil pra-survey kepada 30 orang di Kota Yogyakarta menunjukkan bahwa 86\% orang mengetahui tentang fintech dan $76 \%$ yang menggunakannya. Mereka yang belum menggunakan fintech merasa tidak tahu mengenai financial technology dan merasa belum membutuhkannya. Sebagian besar financial technology yang diketahui dan digunakan oleh masyarakat Kota Yogyakarta adalah payment fintech karena mudah untuk digunakan, praktis, cepat, 


\section{JURNAL NOMINAL / VOLUME VIII NOMOR 2 / TAHUN 2019}

efektif dan efisien, serta tuntutan zaman yang sekarang serba digital.

Penelitian terkait financial technology dapat membantu organisasi untuk merancang kebijakan yang paling efektif serta mengetahui partisipasi individu untuk menggunakan layanan tersebut. Dengan demikian, peneliti memilih Innovation Diffusion Theory (IDT) sebagai dasar untuk meneliti faktor yang mempengaruhi minat individu menggunakan financial technology di Kota Yogyakarta.

Teori difusi inovasi pertama kali dipopulerkan oleh Everett M. Rogers tahun 1983 melalui bukunya yang berjudul Diffusion of Innovation. Difusi didefinisikan sebagai proses dimana suatu inovasi dikomunikasikan melalui saluran tertentu dalam jangka waktu tertentu di antara para anggota suatu sistem sosial. Inovasi adalah suatu gagasan, praktek, atau benda yang dianggap atau dirasa baru oleh individu atau kelompok masyarakat.

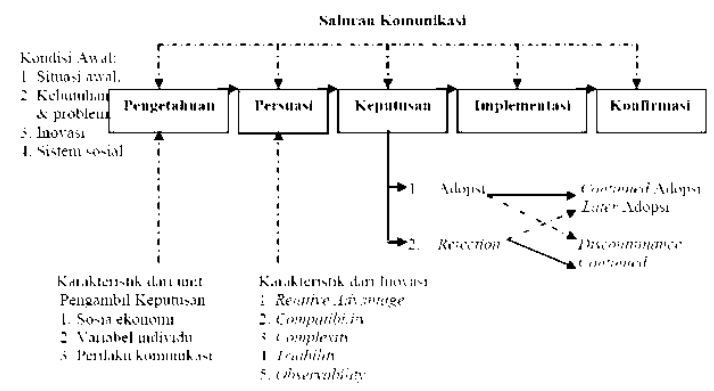

Gambar 1. Model Pengambilan Keputusan Inovasi (Rogers, 2003)

Dalam konteks difusi inovasi menuju adopsi final Rogers (2003) menawarkan karakteristik yang dapat membantu untuk mengurangi ketidakpastian tentang inovasi sehingga mempengaruhi tingkat adopsi individu terhadap produk baru. Dalam perspektif Rogers, karakteritik inovasi ini dapat mempengaruhi individu terhadap tingkat adopsi atau rate of adoption. Tingkat adopsi atau rate of adoption merupakan kecepatan relatif sebuah inovasi itu diadopsi oleh anggota sistem sosial.

Rogers (2003) menerangkan bahwa karakteristik inovasi tersebut adalah keunggulan relatif (relative advantage), kesesuaian (compatibility), kerumitan (complexity), dapat diuji coba (trialability), dan dapat dilihat (observability). Lima karakteristik tersebut dalam proses keputusan inovasi beradaa pada tahap persuasi (persuasion stage) yang sangat penting peranannya dalam keputusan inovasi.

Syafi'i dan Widijoko (2016) menyatakan bahwa perilaku seseorang dalam menggunakan uang elektronik dipengaruhi minat atau intensi. Hal ini menunjukkan bahwa minat dapat digunakan sebagai prediksi seseorang dalam berperilaku. Dengan demikian, faktor-faktor yang mempengaruhi minat individu menggunakan layanan financial technology merupakan hal penting untuk diteliti karena perilaku seseorang dalam menggunakan teknologi baru dapat 


\section{JURNAL NOMINAL / VOLUME VIII NOMOR 2 / TAHUN 2019}

menentukan individu itu sendiri dalam menyikapi teknologi yang tersedia.

Berdasarkan latar belakang tersebut, peneliti bermaksud untuk menguji faktorfaktor yang diperkirakan mempengaruhi minat individu dalam menggunakan layanan financial technology dengan sampel penelitian pengguna layanan financial technology di Kota Yogyakarta. Faktor yang digunakan antara lain keunggulan relatif (relative advantage), kesesuaian (compatibility), kerumitan (complexity), dapat diuji coba (trialability), dan dapat dilihat (observability). Oleh karena itu, dalam upaya mengetahui peranan financial technology di Kota Yogyakarta, peneliti membahas permasalahan tersebut dengan judul "Determinan Minat Individu Menggunakan Layanan Financial Technology dengan Kerangka Innovation Diffusion Theory".

\section{KAJIAN LITERATUR}

Keunggulan relatif (relative advantage) adalah tingkat kelebihan suatu inovasi, apakah lebih baik dari inovasi yang sebelumnya atau dari hal-hal yang biasa dilakukan (Rogers, 2003). Kelebihan suatu inovasi menjadi nilai tambah bagi pengguna financial technology dalam menggunakan inovasi tersebut. Dengan adanya keunggulan dalam suatu inovasi financial technology, individu akan sangat cepat untuk mengadopsi atau menggunakan layanan tersebut karena tingkat layanan financial technology tersebut dipersepsikan lebih baik daripada ide inovasi sebelumnya. Pengaruh relative advantage terhadap minat menggunakan layanan financial technology ini memandang bahwa layanan financial technology menawarkan banyak keunggulan diantaranya lebih efektif dan efisien serta nyaman untuk digunakan.

$\mathrm{H} 1 \quad$ : Relative advantage berpengaruh positif terhadap minat individu menggunakan layanan financial technology.

Kesesuaian (compatibility) adalah tingkat keserasian dari suatu inovasi, apakah dianggap konsisten atau sesuai dengan nilai-nilai, pengalaman dan kebutuhan yang ada (Rogers, 2003). Compatibility sangat berpengaruh dalam pengambilan keputusan individu untuk menggunakan suatu inovasi. Layanan financial technology yang sesuai dengan nilai material dan vital yang berguna bagi jasmani individu dapat dimanfaatkan untuk memenuhi kebutuhan sehari-harinya.

Layanan financial technology yang muncul saat ini sesuai dengan norma agama karena tidak bertentangan dengan larangan Tuhan yang ada, sesuai dengan norma hukum yang berlaku karena layanan financial technology memiliki dasar hukum yang telah diatur oleh Bank Indonesia (BI) dan Otoritas Jasa Keuangan (OJK). Kesesuaian dengan pengalaman masa lalu 


\section{JURNAL NOMINAL / VOLUME VIII NOMOR 2 / TAHUN 2019}

individu juga mempengaruhi dalam mengadopsi layanan financial technology. Apabila layanan financial technology lebih mudah untuk digunakan dan lebih menyenangkan dibandingkan dengan sistem konvensional sebelumnya, maka individu tersebut akan lebih cepat untuk menggunakan layanan financial technology. Hal ini menunjukkan hadirnya layanan financial technology dapat dikatakan sesuai dengan kebutuhan masyarakat dalam hal bertransaksi dan tidak bertentangan dengan nilai-nilai dan norma-norma sosial yang berlaku.

\section{$\mathrm{H} 2$ : Compatibility berpengaruh positif terhadap minat individu menggunakan layanan financial technology.}

Complexity adalah tingkat kerumitan dari suatu inovasi untuk diadopsi, seberapa sulit memahami dan menggunakan inovasi. Semakin mudah suatu inovasi dimengerti dan dipahami oleh adopter, maka semakin cepat inovasi tersebut diadopsi. Untuk mengadopsi suatu teknologi, individu akan melihat kemudahan teknologi yang ditawarkan berdasarkan pengalaman. Apabila teknologi keuangan yang ditawarkan sangat mudah dipahami dan membantu dalam bertransaksi kegiatan sehari-hari, maka individu akan menggunakan layanan tersebut, begitu sebaliknya apabila layanan teknologi keuangan yang ditawarkan justru mempersulit individu dalam melakukan kegiatan transaksi maka individu tersebut tidak akan berminat untuk menggunakan layanan financial technology yang ditawarkan.

H3 : Complexity berpengaruh negatif terhadap minat individu menggunakan layanan financial technology.

Trialability merupakan tingkat apakah suatu inovasi dapat dicoba terlebih dahulu atau harus terikat untuk menggunakannya. Suatu inovasi yang dapat diuji coba pada keadaan sesungguhnya terlebih dahulu pada umumnya akan lebih cepat diadopsi (Rogers, 2003). Individu akan mencoba menggunakan layanan financial technology yang baru untuk mengetahui apakah layanan yang dibutuhkan dapat dipenuhi dan cara menggunakannya harus mudah untuk dipelajari.
H4 : Trialability berpengaruh positif terhadap minat individu menggunakan layanan financial technology.

Observability adalah tingkat bagaimana hasil penggunaan suatu inovasi dapat dilihat oleh orang lain. Semakin mudah seseorang melihat hasil suatu inovasi, semakin besar kemungkinan inovasi diadopsi oleh orang atau sekelompok orang (Rogers, 2003). Masyarakat umumnya dapat melihat bahwa layanan financial 


\section{JURNAL NOMINAL / VOLUME VIII NOMOR 2 / TAHUN 2019}

technology memberikan manfaat bagi penggunanya dalam bertransaksi, sehingga dapat mendorong individu lain untuk menggunakan layanan financial technology tersebut.

H5 : Observability berpengaruh positif terhadap minat individu menggunakan layanan financial technology.

\section{METODE PENELITIAN}

\section{Jenis Penelitian}

Penelitian ini merupakan penelitian penjelas (explanatory research) menggunakan pendekatan kuantitatif yang bertujuan menjelaskan ada atau tidaknya hubungan kausal antara variabel-variabel yang diteliti melalui suatu pengujian hipotesis yang diajukan (Singarimbun dan Effendy, 1995:5). Penelitian ini dilakukan untuk menganalisis bagaimana relative advantage, compatibility, complexity, trialability, dan observability berpengaruh terhadap minat individu menggunakan layanan financial technology di Kota Yogyakarta. Penelitian ini penting ketika ada fakta yang diketahui namun belum banyak informassi yang menjelaskan permasaalahan atau penelitian di masa lalu (Bougie dan Sekaran, 2013:96).

\section{Waktu dan Tempat Penelitian}

Penelitian ini dilakukan di Kota Yogyakarta. Waktu pelaksanaan penelitian ini dilakukan pada bulan Mei-Juni 2019.

\section{Subjek Penelitian}

Populasi dalam penelitian ini adalah pengguna layanan financial technology di Kota Yogyakarta dan sampel yanag digunakan dalam penelitian ini adalah 100 pengguna layanan financial technology di Kota Yogyakarta. Penelitian ini menggunakan teknik convenience sampling dimana responden bersedia untuk digunakan sebagai sampel.

\section{Prosedur}

Penelitian dilakukan dengan menyebar instrumen penelitian berupa kuesioner online pada grup-grup media sosial dimana individu yang menggunakan layanan financial technology bersedia menjadi responden.

\section{Data, Intrumen, dan Teknik} Pengumpulan

\section{a). Data}

Data yang digunakan dalam penelitian ini adalah data primer. Teknik yang digunakan untuk mengumpulkan data yaitu survey dengan menyebarkan kuesioner. Instrumen penelitian yang digunakan dalam penelitian ini berupa angket tertutup karena responden hanya memberikan tanda checlist $(\sqrt{ })$ pada alternatif jawaban yang telah disediakan. Responden diminta melakukan penilaian berupa angket tentang relative advantage, compatibility, complexity, trialability, dan observability terhadap minat individu menggunakan layanan fintech. 


\section{JURNAL NOMINAL / VOLUME VIII NOMOR 2 / TAHUN 2019}

Pada kuesioner relative advantage, peneliti memodifikasi kuesioner bedasarkan indikator yang dijelaskan oleh Rogers (2003). Untuk kuesioner compatibility, peneliti memodifikasi kuesioner yang digunakan oleh Nancy L. Atkinson (2007), dan untuk kuesioner complexity, trialability, dan observability, peneliti memodifikasi kuesioner yang digunakan oleh Sholahuddin (2017).

\section{b). Teknik Analisis Data}

Penelitian ini diuji menggunakan statistik deskriptif untuk memberikan gambaran terhadap sampel secara apa adanya, tanpa bermaksud untuk membuat kesimpulan yang berlaku umum. Data penelitian ini diolah menggunakan analisis Partial Least Square (PLS). Pengujian validitas pada penelitian ini menggunakan validitas konvergen dan diskriminan dan pengujian reliabilitas dalam penelitian ini dilihat pada nilai cronbanch's alpha dan nilai composite reliability (Jogiyanto dan Abdillah, 2016:61). Model struktural pada penelitian ini dapat diukur menggunakan nilai determinasi $\mathrm{R}^{2}$ dan nilai koefisien path atau $t$-values tiap path untuk uji signifikansi antar konstruk (Ghozali, 2001:87).

\section{HASIL PENELITIAN DAN PEMBAHASAN}

Data penelitian ini dianalisis dengan teknik analisis data yang telah dipilih untuk mencapai tujuan penelitian. Ringkasan kuesioner yang diterima disajikan pada tabel berikut ini:

Tabel 1. Hasil Pengumpulan Data

\begin{tabular}{lcc}
\hline \multicolumn{1}{c}{ Keterangan } & $\begin{array}{c}\text { Jumla } \\
\text { h }\end{array}$ & $(\boldsymbol{\%})$ \\
\hline Kuesioner yang diterima & 105 & $\begin{array}{c}100 \\
\%\end{array}$ \\
$\begin{array}{l}\text { Kuesioner yang tidak layak } \\
\text { Kuesioner yang memenuhi } \\
\text { syarat }\end{array}$ & 5 & $5 \%$ \\
\hline
\end{tabular}

Sumber: data primer, diolah 2019

Berdasarkan tabel di atas kuesioner yang diterima sebanyak 105 kuesioner atau sebesar $100 \%$ dan terdapat kuesioner yang tidak memenuhi syarat sebanyak 5 kuesioner atau sebesar 5\%. Jadi, kuesioner yang dapat digunakan adalah 100 kuesioner atau sebesar $95 \%$.

Total responden yang didapatkan sejumlah 100 responden yang terdiri dari 53 responden perempuan atau sebesar 53\% dan 47 responden laki-laki atau sebesar 47\%. Jumlah responden perempuan lebih tinggi $6 \%$ daripada responden laki-laki. Dalam penelitian ini, hasil tersebut menunjukkan bahwa perempuan lebih banyak menggunakan layanan financial technology dibandingkan dengan laki-laki.

Sebagian besar responden yang menggunakan layanan financial technology berusia 20 - 30 tahun dengan jumlah 83 responden atau $83 \%$. Hal ini menunjukkan bahwa layanan financial technology banyak digunakan oleh kaum muda yang masih produktif. 


\section{JURNAL NOMINAL / VOLUME VIII NOMOR 2 / TAHUN 2019}

Tabel 2. Karakteristik Responden

\begin{tabular}{|c|c|c|}
\hline $\begin{array}{c}\text { Karakteristik } \\
\text { Responden }\end{array}$ & $\begin{array}{c}\text { Jumla } \\
\text { h }\end{array}$ & $(\%)$ \\
\hline \multicolumn{3}{|c|}{ Berdasarkan jenis kelamin } \\
\hline Laki-laki & 47 & $47 \%$ \\
\hline Perempuan & 53 & $\begin{array}{c}53 \% \\
100\end{array}$ \\
\hline Total & 100 & $\%$ \\
\hline \multicolumn{3}{|l|}{ Berdasarkan usia } \\
\hline$<20$ tahun & 3 & $3 \%$ \\
\hline 20 - 30 tahun & 83 & $83 \%$ \\
\hline $31-40$ tahun & 7 & $7 \%$ \\
\hline $41-50$ tahun & 3 & $3 \%$ \\
\hline$>50$ tahun & 4 & $\begin{array}{l}4 \% \\
100\end{array}$ \\
\hline Total & 100 & $\%$ \\
\hline \multicolumn{3}{|c|}{ Berdasarkan tingkat pendidikan } \\
\hline SD/Sederajat & 0 & $0 \%$ \\
\hline SMP/Sederajat & 0 & $0 \%$ \\
\hline SMA/SMK/Sederajat & 38 & $38 \%$ \\
\hline Diploma III & 10 & $10 \%$ \\
\hline Sarjana (S1) & 47 & $47 \%$ \\
\hline Lainnya & 5 & $\begin{array}{l}5 \% \\
100\end{array}$ \\
\hline Total & 100 & $\%$ \\
\hline \multicolumn{3}{|l|}{ Berdasarkan pekerjaan } \\
\hline PNS/TNI/POLRI & 16 & $16 \%$ \\
\hline Pegawai swasta & 24 & $24 \%$ \\
\hline Pelajar//Mahasiswa & 40 & $40 \%$ \\
\hline Wirausaaha & 13 & $13 \%$ \\
\hline Ibu Rumah Tangga & 1 & $1 \%$ \\
\hline Lainnya & 6 & $\begin{array}{l}6 \% \\
100\end{array}$ \\
\hline Total & 100 & $\%$ \\
\hline
\end{tabular}

Sumber: data primer, diolah 2019

Responden didominasi oleh sarjana

(S1) sebanyak 47 responden atau sebesar

47\%. Berdasarkan tabel diatas, tingkat

pendidikan responden dianggap memadai karena minimal tingkat pendidikan yang menggunakan layanan financial technology di Kota Yogyakarta adalah pelajar SMA/SMK/Sederajat.

Responden yang menggunakan layanan financial technology adalah pelajar/mahasiswa dengan jumlah 40 responden atau sebesar $40 \%$ dan diikuti oleh pegawai swasta sebanyak 24 responden atau sebesar $24 \%$.

Tabel 3. Karakteristik Responden Berdasarkan Aplikasi Layanan Financial Technology yang Digunakan

\begin{tabular}{|c|c|c|}
\hline Layanan Fintech & $\begin{array}{c}\text { Jumla } \\
\text { h }\end{array}$ & $(\%)$ \\
\hline \multicolumn{3}{|c|}{ Layanan pembayaran online } \\
\hline Go-Pay & 73 & $22 \%$ \\
\hline OVO & 57 & $17 \%$ \\
\hline Dana & 38 & $11 \%$ \\
\hline LinkAja & 20 & $6 \%$ \\
\hline Lainnya & 8 & $2 \%$ \\
\hline Total & 196 & $59 \%$ \\
\hline \multicolumn{3}{|c|}{ Layanan pinjaman keuangan digital } \\
\hline Investree & 2 & $1 \%$ \\
\hline Kredivo & 8 & $2 \%$ \\
\hline UangTeman & 8 & $2 \%$ \\
\hline Modalku & 8 & $2 \%$ \\
\hline Lainnya & 2 & $1 \%$ \\
\hline Total & 28 & $8 \%$ \\
\hline Layanan Fintech & $\underset{\mathrm{h}}{\mathrm{Jumla}}$ & $(\%)$ \\
\hline \multicolumn{3}{|c|}{$\begin{array}{l}\text { Layanan jasa pembanding keuangan } \\
\text { digital }\end{array}$} \\
\hline Traveloka & 70 & $21 \%$ \\
\hline Cekaja & 3 & $1 \%$ \\
\hline Cermati & 1 & $0 \%$ \\
\hline KreditGogo & 0 & $0 \%$ \\
\hline Lainnya & 3 & $1 \%$ \\
\hline Total & 77 & $23 \%$ \\
\hline \multicolumn{3}{|c|}{ Layanan perencanaan keuangan digital } \\
\hline Finansialku & 19 & $6 \%$ \\
\hline Bareksa & 8 & $2 \%$ \\
\hline TanamDuit & 3 & $1 \%$ \\
\hline Cekpremi & 1 & $0 \%$ \\
\hline Lainnya & 2 & $1 \%$ \\
\hline \multirow[t]{3}{*}{ Total } & 33 & $10 \%$ \\
\hline & & 100 \\
\hline & 334 & $\%$ \\
\hline
\end{tabular}

Sumber: data primer, diolah 2019

Dari hasil di atas, sebagian besar aplikasi yang digunakan oleh responden adalah aplikasi layanan pembayaran online sebesar 59\%. Dari aplikasi layanan pembayaran online yang digunakan oleh responden, Go-Pay adalah aplikasi yang 
banyak digunakan dibandingkan aplikasi layanan pembayaran online yang lain.

Uji validitas konstruk dengan PLS dilakukan dengan analisis validitas konvergen dan validitas diskriminan. Hasil pengujian validitas dapat dilihat berdasarkan tabel berikut:

Tabel 4. Nilai AVE

\begin{tabular}{lcc}
\hline \multicolumn{1}{c}{ Variabel } & AVE & Keterangan \\
\hline Relative Advantage & 0,739 & Valid \\
Compatibility & 0,827 & Valid \\
Complexity & 0,781 & Valid \\
Trialability & 0,608 & Valid \\
$\begin{array}{l}\text { Observability } \\
\text { Minat Individu }\end{array}$ & 0,568 & Valid \\
$\begin{array}{l}\text { Menggunakan } \\
\text { Fintech }\end{array}$ & 0,622 & Valid \\
Sumber: data primer, diolah 2019 &
\end{tabular}

Tabel 5. Faktor Loading

\begin{tabular}{|c|c|c|c|c|c|c|}
\hline & RA & CP & CM & TR & OB & MI \\
\hline RA. & 0,8 & & & & & \\
\hline $\mathbf{1}$ & 41 & & & & & \\
\hline RA. & 0,9 & & & & & \\
\hline 2 & 39 & & & & & \\
\hline RA. & 0,8 & & & & & \\
\hline $\mathbf{3}$ & 24 & & & & & \\
\hline RA. & 0,8 & & & & & \\
\hline 4 & 03 & & & & & \\
\hline RA. & 0,7 & & & & & \\
\hline 5 & 90 & & & & & \\
\hline \multirow{3}{*}{$\begin{array}{c}\text { RA. } \\
6\end{array}$} & 0,9 & & & & & \\
\hline & 46 & & & & & \\
\hline & RA & CP & $\mathbf{C M}$ & TR & OB & MI \\
\hline CP. & & 0,9 & & & & \\
\hline 1 & & 62 & & & & \\
\hline CP. & & 0,9 & & & & \\
\hline 2 & & 71 & & & & \\
\hline CP. & & 0,9 & & & & \\
\hline 3 & & 04 & & & & \\
\hline CP. & & 0,8 & & & & \\
\hline 4 & & 77 & & & & \\
\hline CP. & & 0,9 & & & & \\
\hline 5 & & 52 & & & & \\
\hline CP. & & 0,7 & & & & \\
\hline 6 & & 74 & & & & \\
\hline CM & & & 0,8 & & & \\
\hline .1 & & & 18 & & & \\
\hline
\end{tabular}

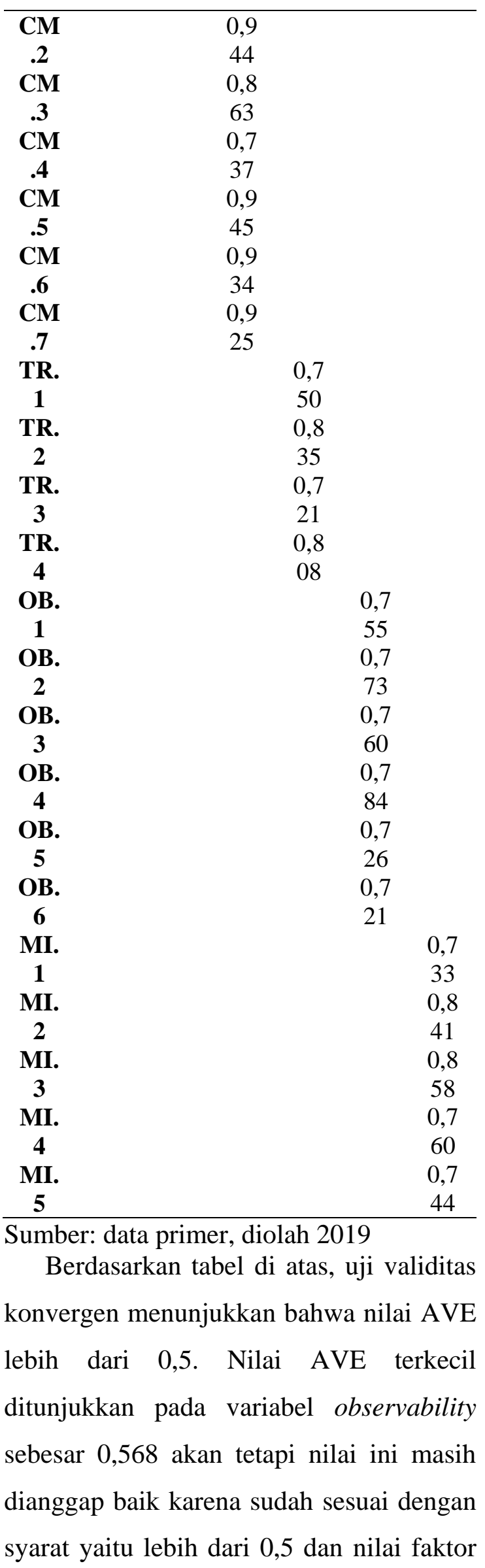


loading lebih dari 0,7 yang artinya memenuhi parameter uji validitas konvergen. Nilai paling kecil ditunjukkan pada TR.3 (Trialability 3) dan OB.6 (Observability 6) yaitu sebesar 0,721.

Tabel 6. Nilai Cross Loading

\begin{tabular}{ccccccc}
\hline & RA & CP & CM & TR & OB & MI \\
\hline RA. & 0,8 & 0,6 & 0,6 & 0,3 & 0,5 & 0,6 \\
$\mathbf{1}$ & 41 & 65 & 66 & 94 & 30 & 34 \\
$\mathbf{R A .}$ & 0,9 & 0,8 & 0,8 & 0,4 & 0,6 & 0,7 \\
$\mathbf{2}$ & 39 & 04 & 12 & 22 & 15 & 40 \\
\hline & $\mathbf{R A}$ & $\mathbf{C P}$ & $\mathbf{C M}$ & $\mathbf{T R}$ & $\mathbf{O B}$ & $\mathbf{M I}$ \\
\hline $\mathbf{R A .}$ & 0,8 & 0,7 & 0,8 & 0,4 & 0,6 & 0,6 \\
$\mathbf{3}$ & 24 & 41 & 43 & 67 & 15 & 62 \\
$\mathbf{R A .}$ & 0,8 & 0,6 & 0,7 & 0,3 & 0,5 & 0,5 \\
$\mathbf{4}$ & 03 & 46 & 47 & 83 & 94 & 53 \\
$\mathbf{R A .}$ & 0,7 & 0,6 & 0,6 & 0,3 & 0,5 & 0,5 \\
$\mathbf{5}$ & 90 & 08 & 31 & 75 & 55 & 60 \\
$\mathbf{R A .}$ & 0,9 & 0,8 & 0,8 & 0,4 & 0,6 & 0,7 \\
$\mathbf{6}$ & 46 & 56 & 56 & 80 & 75 & 87 \\
$\mathbf{C P .}$ & 0,8 & 0,9 & 0,9 & 0,5 & 0,7 & 0,8 \\
$\mathbf{1}$ & 35 & 62 & 06 & 93 & 27 & 39 \\
$\mathbf{C P .}$ & 0,8 & 0,9 & 0,9 & 0,5 & 0,7 & 0,8 \\
$\mathbf{2}$ & 50 & 71 & 34 & 79 & 35 & 38 \\
$\mathbf{C P .}$ & 0,7 & 0,9 & 0,8 & 0,5 & 0,6 & 0,7 \\
$\mathbf{3}$ & 43 & 04 & 48 & 23 & 56 & 62 \\
$\mathbf{C P .}$ & 0,7 & 0,8 & 0,9 & 0,5 & 0,6 & 0,7 \\
$\mathbf{4}$ & 41 & 77 & 25 & 71 & 75 & 15 \\
$\mathbf{C P .}$ & 0,8 & 0,9 & 0,9 & 0,6 & 0,7 & 0,8 \\
$\mathbf{5}$ & 05 & 52 & 12 & 27 & 66 & 42 \\
$\mathbf{C P .}$ & 0,6 & 0,7 & 0,7 & 0,3 & 0,4 & 0,5 \\
$\mathbf{6}$ & 11 & 74 & 75 & 89 & 95 & 82 \\
$\mathbf{C M}$ & 0,8 & 0,7 & 0,8 & 0,4 & 0,6 & 0,6 \\
$\mathbf{. 1}$ & 02 & 08 & 18 & 80 & 18 & 50 \\
$\mathbf{C M}$ & 0,8 & 0,9 & 0,9 & 0,5 & 0,7 & 0,8 \\
$\mathbf{. 2}$ & 40 & 63 & 44 & 72 & 09 & 15 \\
$\mathbf{C M}$ & 0,7 & 0,8 & 0,8 & 0,5 & 0,6 & 0,7 \\
$\mathbf{. 3}$ & 25 & 89 & 63 & 30 & 42 & 40 \\
$\mathbf{C M}$ & 0,7 & 0,6 & 0,7 & 0,3 & 0,5 & 0,5 \\
$\mathbf{. 4}$ & 90 & 33 & 37 & 79 & 88 & 44 \\
$\mathbf{C M}$ & 0,7 & 0,9 & 0,9 & 0,5 & 0,6 & 0,7 \\
$\mathbf{. 5}$ & 62 & 02 & 45 & 76 & 93 & 08 \\
$\mathbf{C M}$ & 0,8 & 0,9 & 0,9 & 0,5 & 0,7 & 0,8 \\
$\mathbf{. 6}$ & 50 & 71 & 34 & 79 & 35 & 38 \\
$\mathbf{C M}$ & 0,7 & 0,8 & 0,9 & 0,5 & 0,6 & 0,7 \\
$\mathbf{. 7}$ & 41 & 77 & 25 & 71 & 75 & 15 \\
$\mathbf{T R .}$ & 0,3 & 0,3 & 0,3 & 0,7 & 0,5 & 0,4 \\
$\mathbf{1}$ & 13 & 65 & 65 & 50 & 40 & 58 \\
$\mathbf{T R .}$ & 0,4 & 0,5 & 0,5 & 0,8 & 0,6 & 0,5 \\
$\mathbf{2}$ & 19 & 25 & 20 & 35 & 23 & 54
\end{tabular}

$\begin{array}{ccccccc}\text { TR. } & 0,3 & 0,4 & 0,4 & 0,7 & 0,6 & 0,5\end{array}$

$\begin{array}{lllllll}3 & 36 & 43 & 21 & 21 & 92 & 57\end{array}$

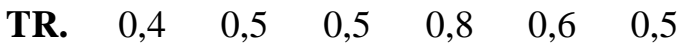

$\begin{array}{lllllll}4 & 52 & 43 & 53 & 08 & 14 & 50\end{array}$

OB. $\quad 0,3 \quad 0,3 \quad 0,4 \quad 0,5 \quad 0,7 \quad 0,5$

$\begin{array}{lllllll}1 & 97 & 95 & 20 & 82 & 55 & 05\end{array}$

OB. $\quad 0,8 \quad 0,9 \quad 0,9 \quad 0,6 \quad 0,7 \quad 0,8$

$\begin{array}{lllllll}2 & 57 & 77 & 45 & 17 & 73 & 58\end{array}$

OB. $\quad 0,4 \quad 0,4 \quad 0,4 \quad 0,5 \quad 0,7 \quad 0,5$

$\begin{array}{lllllll}3 & 77 & 49 & 46 & 56 & 60 & 62\end{array}$

OB. $\quad 0,4 \quad 0,4 \quad 0,5 \quad 0,6 \quad 0,7 \quad 0,5$

$\begin{array}{lllllll}4 & 80 & 82 & 09 & 64 & 84 & 64\end{array}$

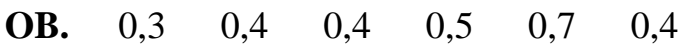

$\begin{array}{lllllll}5 & 80 & 30 & 44 & 95 & 26 & 62\end{array}$

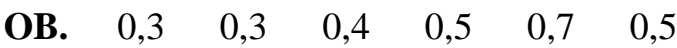

$\begin{array}{lllllll}6 & 34 & 96 & 11 & 85 & 21 & 02\end{array}$

MI. $\quad 0,5 \quad 0,5 \quad 0,5 \quad 0,5 \quad 0,6 \quad 0,7$

$\begin{array}{lllllll}1 & 17 & 47 & 48 & 35 & 12 & 33\end{array}$

MI. $\quad 0,5 \quad 0,6 \quad 0,6 \quad 0,5 \quad 0,6 \quad 0,8$

$\begin{array}{lllllll}2 & 50 & 67 & 17 & 34 & 28 & 41\end{array}$

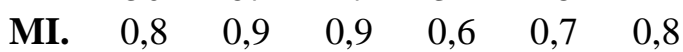

$\begin{array}{lllllll}3 & 57 & 77 & 45 & 17 & 73 & 58\end{array}$

MI. $\quad 0,4 \quad 0,4 \quad 0,4 \quad 0,5 \quad 0,5 \quad 0,7$

$\begin{array}{lllllll}4 & 92 & 97 & 82 & 15 & 76 & 60\end{array}$

MI. $\quad 0,5 \quad 0,4 \quad 0,4 \quad 0,4 \quad 0,5 \quad 0,7$

$\begin{array}{lllllll}5 & 19 & 97 & 90 & 75 & 12 & 44\end{array}$

Sumber: data primer, diolah 2019

Hasil nilai cross loading pada tabel di atas menunjukkan bahwa nilai korelasi indikator dengan konstruk lebih tinggi dibandingkan dengan konstruk lainnya. Nilai cross loading setiap indikator konstruk sudah sesuai dengan yang disarankan, yaitu di atas 0,7. Dengan demikian, dapat disimpulkan bahwa data pada hasil uji ini memiliki validitas diskriminan yang baik.

Uji reliabilitas diukur dengan dua kriteria, yaitu composite reliability dan crobanch's alpha dari blok indikator yang mengukur konstruk. Konstruk dinyatakan reliabel jika nilai composite reliability dan crobanch's alpha di atas 0,7 (Ghozali, 2001). 
Hasil dari composite reliability dan crobanch's alpha pada tabel di atas yang dihasilkan semua konstruk sangat baik, yaitu di atas $0,7(>0,7)$ sehingga dapat disimpulkan bahwa semua indikator konstruk adalah reliabel dan memenuhi uji reliabilitas.

Tabel 7. Nilai Cronbanch's Alpha dan Composite Reliability

\begin{tabular}{|c|c|c|c|}
\hline Variabel & $\begin{array}{c}\text { Cronb } \\
\text { ach's } \\
\text { Alpha }\end{array}$ & $\begin{array}{c}\text { Comp } \\
\text { osite } \\
\text { Relia } \\
\text { bility }\end{array}$ & Ket \\
\hline $\begin{array}{l}\text { Relative } \\
\text { Advantage }\end{array}$ & 0,928 & 0,944 & Reliabel \\
\hline Compatibility & 0057 & 0,966 & Reliabel \\
\hline Complexity & 0,952 & 0,961 & Reliabel \\
\hline Trialability & 0,784 & 0,861 & Reliabel \\
\hline $\begin{array}{l}\text { Observability } \\
\text { Minat Individu }\end{array}$ & 0,851 & 0,887 & Reliabel \\
\hline $\begin{array}{l}\text { Menggunakan } \\
\text { Layanan } \\
\text { Fintech }\end{array}$ & 0,849 & 0,891 & Reliabel \\
\hline
\end{tabular}

Sumber: data primer, diolah 2019

Pada uji model struktural dilakukan dengan melihat nilai R-square yang merupakan uji goodness-fit model dan selanjutnya melihat signifikansi pengaruh antar konstruk dengan melihat hasil nilai pada path coefficients (Ghozali, 2001).

Tabel 8. Nilai $\mathrm{R}^{2}$

\begin{tabular}{l}
\hline Variabel \\
\hline $\begin{array}{l}\text { Minat Individu Menggunakan } \\
\text { Layanan Fintech }\end{array}$ \\
$\begin{array}{l}\text { Sumber: data primer, diolah } 2019 \\
\text { Berdasarkan hasil tersebut, dapat }\end{array}$ \\
diketahui bahwa $\mathrm{R}^{2}$ untuk konstruk minat \\
individu menggunakan layanan financial \\
technology adalah sebesar 0,803. Hal ini \\
menunjukkan bahwa minat individu \\
menggunakan layanan financial technology
\end{tabular}

di Kota Yogyakarta dipengaruhi oleh konstruk relative advantage, compatibility, complexity, trialability, observability sebesar $80,3 \%$ dan sisanya $19,7 \%$ dipengaruhi oleh variabel lain diluar model yang diajukan pada penelitian ini.

Tabel 9. Hasil Path Coeffisients

\begin{tabular}{cccc}
\hline Hipotesis & $\begin{array}{c}\text { Original } \\
\text { Sample }\end{array}$ & $\begin{array}{c}\boldsymbol{T} \\
\text { Statistics }\end{array}$ & $\begin{array}{c}\boldsymbol{P} \\
\text { Value }\end{array}$ \\
\hline $\mathrm{RA} \rightarrow \mathrm{MI}$ & 0,282 & 2,556 & 0,005 \\
$\mathrm{CP} \rightarrow \mathrm{MI}$ & 0,868 & 3,909 & 0,000 \\
$\mathrm{CM} \rightarrow \mathrm{MI}$ & $-0,559$ & 2,124 & 0,017 \\
$\mathrm{TR} \rightarrow \mathrm{MI}$ & 0,151 & 1,745 & 0,041 \\
$\mathrm{OB} \rightarrow \mathrm{MI}$ & 0,255 & 2,502 & 0,006 \\
\hline
\end{tabular}

Sumber: Data primer diolah, 2019

Hasil pengujian pada tabel di atas menunjukkan bahwa semua hipotesis diterima dengan p-value $<0,05$, yaitu relative advantage, compatibility, complexity, trialability, dan observability terhadap minat individu menggunakan layanan financial technology.

Hipotesis pertama diterima karena koefisien korelasi memiliki nilai positif sebesar 0,282 dan nilai signifikansi 0,005. Artinya, keunggulan relatif (relative advantage) berpengaruh positif terhadap minat individu menggunakan layanan financial technology. Penelitian ini sesuai dengan teori yang dijelaskan oleh Rogers (2003) yang menyatakan bahwa lebih besar keuntungan relatif suatu inovasi, maka semakin cepat inovasi tersebut diadopsi. Penelitian ini juga sejalan dengan penelitian 


\section{JURNAL NOMINAL / VOLUME VIII NOMOR 2 / TAHUN 2019}

yang dilakukan oleh Lee et.al (2011) dan Sholahuddin (2017).

Menurut individu pengguna layanan financial technology di Kota Yogyakarta, keuntungan relatif yang paling menonjol adalah keuntungan yang bersifat ekonomis. Dengan demikian, financial technology telah dianggap sepenuhnya unggul untuk mempermudah individu dalam bertransaksi karena dapat meningkatkan efektivitas individu dalam bertransaksi dan menumbuhkan rasa percaya diri pada individu karena merasa lebih modern, serta menciptakan kenyamanan dan kepuasan terhadap individu yang menggunakan layanan financial technology.

Hipotesis kedua diterima karena koefisien korelasi memiliki nilai positif sebesar 0,868 dan nilai signifikansi 0,000 sehingga kesesuaian (compatibility) berpengaruh positif terhadap minat individu menggunakan layanan financial technology. Penelitian ini sesuai dengan pendapat Rogers (2003) yang menyatakan bahwa ide yang tidak compatible dengan ciri-ciri sosial yang menonjol tidak akan diadopsi secepat ide yang compatible. Penelitian ini juga sejalan dengan penelitian yang dilakukan oleh Cho (2006) dan Ahmad (2016).

Layanan financial technology sesuai dengan era saat ini yang serba digital, sesuai dengan pengalaman, dan nilai-nilai dan norma yang berlaku di masyarakat, dan membantu individu untuk belajar lebih banyak tentang teknologi karena sesuai dengan tuntutan zaman sekarang yang hampir semuanya mengandalkan teknologi. Dengan demikian, sebuah inovasi yang sesuai dengan nilai-nilai dan norma-norma di dalam sebuah sistem sosial pasti akan cepat diadopsi karena dianggap konsisten.

Hipotesis ketiga diterima karena koefisien korelasi memiliki nilai negatif sebesara -0,559 dan nilai signifikansi 0,017. Artinya, kerumitan (complexity) berpengaruh negatif terhadap minat individu menggunakan layanan financial technology. Penelitian ini sesuai dengan pendapat Rogers (2003) yang menerangkan bahwa semakin rumit suatu inovasi bagi seseorang, maka semakin lambat seseorang untuk mengadopsinya. Penelitian ini bertentangan dengan penelitian yang dilakukan oleh Tanakinjal et.al(2011), namun sejalan dengan penelitian yang dilakukan oleh Ahmad (2016). Adanya tahapan atau prosedur layanan financial technology yang dirasa rumit dan menyulitkan individu dalam menggunakan. Dengan demikian, semakin rumit layanan financial technology maka semakin lambat individu untuk menggunakannya.

Hipotesis keempat diterima karena koefisien korelasi memiliki nilai positif sebesar 0,151 dan nilai signifikansi 0,041. Artinya, dapat dicoba (trialability) berpengaruh positif terhadap minat 
individu menggunakan layanan financial technology. Penelitian ini sesuai dengan pendapat Rogers (2003) yang menerangkan bahwa inovasi baru yang dapat dicoba biasanya akan lebih cepat untuk diadopsi daripada inovasi yang tidak dapat dicoba terlebih dahulu karena suatu inovasi yang dapat dicoba akan memperkecil resiko bagi adopter. Penelitian ini bertentangan dengan penelitian yang dilakukan oleh Sholahuddin (2017), namun sesuai dengan penelitian yang dilakukan oleh Slyke, et.al. (2002)

Uji coba layanan financial technology penting bagi individu untuk memutuskan apakah layanan financial technology tersebut akan digunakan atau tidak. Dengan melakukan uji coba, informasi petunjuk cara menggunakan layanan financial technology akan didapatkan dengan mudah dan dipelajari dengan cepat. Dengan demikian, layanan financial technology yang dapat diuji coba terlebih dahulu lebih sering diadopsi dibandingkan dengan layanan financial technology yang tidak dapat dicoba terlebih dahulu.

Hipotesis kelima diterima karena koefisien korelasi memiliki nilai positif sebesar 0,255 dan nilai signifikansi 0,006. Artinya, dapat dilihat (observability) berpengaruh positif terhadap minat individu menggunakan layanan financial technology. Penelitian ini sesuai dengan pendapat Rogers (2003) yang menerangkan bahwa observabilitas suatu inovasi menurut anggapan anggota sistem sosial berhubungan positif dengan kecepatan adopsinya. Penelitian ini juga sesuai dengan penelitian yang dilakukan oleh Lee et.al (2011) dan Sholahuddin (2017).

Terlihatnya manfaat layanan financial technology bagi orang lain, mudahnya mengajarkan cara menggunakan layanan financial technology kepada orang lain, dan petunjuk penggunaan yang jelas dipandang baik sehingga mempengaruhi individu untuk berminat mengadopsinya. Dengan demikian, semakin mudah individu melihat hasil sebuah inovasi, maka semakin besar kemungkinan mereka untuk menggunakannya.

Hasil penelitian ini mendukung Innovation Diffusion Theory (IDT). Hal ini ditunjukkan dengan pentingnya layanan financial technology dalam memenuhi kebutuhan individu sehari-hari karena pengguna lebih mempertimbangkan kesesuaian dengan zaman sekarang yang serba digital dibandingkan dengan kemudahan penggunaan layanan financial technology. Pengguna juga lebih mempertimbangkan fleksibilitas menggunakan dalam layanan financial technology karena bisa digunakan dimana saja dan kapan saja daripada kemudahan untuk mempelajari dan memahami layanan financial technology. Selain itu, pengguna juga lebih mempertimbangkan keuntungan 


\section{JURNAL NOMINAL / VOLUME VIII NOMOR 2 / TAHUN 2019}

secara ekonomis dari layanan financial technology yang ditawarkan dan tidak mempertimbangkan aspek prestise sosial karena bagi mereka prestise sosial bukanlah hal yang utama dalam menggunakan layanan financial technology.

\section{SIMPULAN DAN SARAN}

\section{Simpulan}

Penelitian ini menunjukkan bahwa secara parsial, relative advantage, compatibility, trialability, dan observability berpengaruh positif terhadap minat individu menggunakan layanan financial technology, sedanagkan complexity berpengaruh negatif terhadap minat individu menggunakan layanan financial technology. Dengan demikian, karakteristik inovasi dalam kerangka Innovation Diffusion Theory yang terdiri dari relative advantage, compatibility, complexity, trialability, dan observability berpengaruh terhadap minat individu menggunakan layanan financial technology.

\section{Saran}

Berdasarkan hasil penelitian, sebaiknya perusahaan layanan financial technology dapat mengoptimalkan layanan financial technology yang berfokus pada keuntungan ekonomis, menyediakan fitur yang lengkap, dan menyederhanakan tampilan fitur aplikasi untuk mempermudah pengguna layanan financial technology.
Bagi peneliti selanjutnya, sebaiknya dapat menyempurnakan model penelitian dengan menggunakan metode wawancara atau mix method, melakukan penelitian serupa dengan kerangka IDT pada tahap yang lain, misalnya tahap implementasi dan konfirmasi, serta mencoba model penelitian pada objek yang lain, misalnya pengambilan keputusan pada inovasi baru.

\section{DAFTAR PUSTAKA}

Accenture. (2016). Fintech and the evolving landscape: landing points for the industry. Accenture.

Ahmad, M. Yahya. (2016). Pengaruh Karakteristik Inovasi Pertanian terhadap Keputusan Adopsi Usaha Tani Sayuran Organik. Journal of Agroscience Vol. 6 No. 2 tahun 2016.

Atkinson, Nancy L. (2017). Developing a Questionnaire to Measure Perceived Attributes of eHealth Innovations. Am J Health Behaw, 31(6):612-621.

Bank Indonesia. (2013). Edukasi dan Perlindungan Konsumen SP. https://www.bi.go.id/id/edukasiperlindungankonsumen/edukasi/produkdan-jasasp/fintech/Pages/default.aspx. Diambil pada 3 Februari 2019.

Bougie, \& Sekaran. (2013). Research Methods for Business: A skill Building Approach Ed. 5. New York: John wiley@Sons.

Cho, V. (2006). A Study of The Roles of Trust and Risks in InformationOriented Online Legal Services Using An Integrated Model. 


\section{JURNAL NOMINAL / VOLUME VIII NOMOR 2 / TAHUN 2019}

Information \& Management, Vol. $43,502-520$.

Google dan TEMASEK. (2018) . Southeast Asia's Internet Economy Hits an Inflection Point. https://www.temasek.com.sg. Diambil 1 Februari 2019.

Ghozali, Imam. (2001). Aplikasi Analisis Multivariate dengan Program SPSS. Semarang: Penerbit UNDIP.

Jogiyanto, H. M. \& Abdillah, W. (2016). Konsep \& Aplikasi PLS (Partial Least Square) untuk Penelitian Empiris. Kota Yogyakarta: BPFE.

Lee, Yi-Hsuan; Hsieh, Yi-Chuan; Hsu, Chia-Ning. (2011). Adding Innovation Diffusion Theory to the Technology Acceptance Model. Supporting

Rogers, Everett M. (2003). Diffusion of Innovation. (5th ed). The Free Press. New York.

Sholahuddin. (2017). Pengaruh Karakteristik Inovasi terhadap Niat Mengadopsi Solopos Epaper. Tesis. Surakarta: Pasca Sarjana Universitas Muhammadiyah Surakarta

Singarimbun, M dan Efendi. (1995). Metode Penelitian Survey. Jakarta: PT Pustaka LP3ES.

Slyke, Craig Van; Lou, Hao; Day, John. (2002). The Impact of Perceived Innovation Characteristics on Intention to Use Groupware. Information Resources Management Journal, Jan-Mar 2002, Vol.15 No.1, Technology Collection pg.5
Syafi'i, A. \& Widijoko, Grace. (2016). Determinan Minat Individu Menggunakan Uang Elektronik: Pendekatan Modifikasi Technology Acceptance Model. Jurnal Ilmiah Mahasiswa FEB UB.

Tanakinjal, Geoffrey; Dean, Kenneth R.; Grya, Brendan J. (2011). Intention to Adopt Mobile Marketing : An Exploratory Study in Labuan Malaysia. Asian Journal of Business Research, Vol. 1, No. 1. 